\title{
Development of Cellulose-based Toys with Moulded Fibre Production Method
}

\author{
Engin Sarıkaya,* and Hakan Demirel \\ In this work, a toy was developed from bleached sulphate pulp via a \\ moulded fibre production technique. Moulded fibre products are generally \\ used to preserve main products from damage during transportation and \\ stow them in a particular order. This work investigated the use of moulded \\ fibre products in daily life as final products. Bleached softwood sulphate \\ pulp was used for the experiments to avoid the potential hygiene problems \\ of using recycled paper for toy production. The physical properties of \\ different degrees of refined sulphate pulp were evaluated during toy \\ sample production. The results indicated that toys produced with bleached \\ softwood sulphate pulp had optimum compression strength (22 kpgf) at \\ the $35 \mathrm{SR}^{\circ}$ freeness level. Produced prototypes satisfied EN 71- \\ 3:2013+A1(2014) in terms of migration element limits.
}

\begin{abstract}
Keywords: Lignocellulosic materials; Moulded products; Biodegradable products; Physical-mechanical properties; Optimization

Contact information: Dentaş Paper Industry Inc., Denizli, Turkey; *Corresponding author: engin.sarikaya@dentaskagit.com.tr
\end{abstract}

\section{INTRODUCTION}

Demand for recyclable and biodegradable materials has increased in the packaging industry and other industries. Moulded fibre products (MFP) are recyclable; thus, they could easily be reused in the paper industry (Wever and Twede 2007).

The first patent for the production of MFP was obtained in 1890 (Keyes 1890), and the first production machinery patent was obtained by M.L. Keyes in 1903 (Keyes 1903). Moulded fibre products became popular and began to develop quickly after being used in packaging applications. After the first production machinery patent, M.L. Keyes obtained a second patent on a further developed version of the machinery within one year (Didone et al. 2017). The production method is similar to that of paper production, as the mould surface becomes covered with fibres via vacuuming of them towards the perforated mould, which is submerged into the pulp slurry. Then, the formed wet product is either dried in ovens or between drying moulds, depending on the production method (Wever and Twede 2007).

Moulded fiber product usage expanded after 1980 due to an increased desire to use eco-friendly and recyclable materials in different industries. The high cushioning properties of MFP allow an expanded range of uses (Didone et al. 2017). The mechanical properties of MFP are often compared with a petroleum-based competitor, i.e. expanded polystyrene (EPS). The cushioning effect, energy absorption, and loading capacity of MFP and EPS are typically in a similar range (Ji et al. 2008). However, it is impossible to exactly define the strength properties of MFP, as the mechanical behavior of each product changes depending on dimensions, geometry, and wall thickness (Didone et al. 2017). 
According to the International Moulded Fibre Association (IMFA), MFPs are classified into four main groups:

a) Type 1 is thick wall MFPs, in which one mould is used for production, the wall thickness is between $5 \mathrm{~mm}$ and $10 \mathrm{~mm}$, and one surface of the product is smoother than the other surface. Generally, they are used to support heavy items such as furniture and vehicle parts.

b) Type 2 is transfer moulded MFPs, which are manufactured using two moulds. One of them is a formation mould, and the other one is a transfer mould. The wall thickness is between $3 \mathrm{~mm}$ and $5 \mathrm{~mm}$, and one surface of the product is smoother than the other surface. This type is generally used to produce egg cartons and trays. With the development of new designs, this type is also used for many types of electronic product packaging, such as cell phones and DVD players. This type is also used in hospital disposables, office equipment, tableware, and fruit and drink trays.

c) Type 3 is thermoformed MFPs, which are sometimes called "thin wall" MFPs. Multiple heated moulds are used to produce this kind of MFP. The wall thickness is between $2 \mathrm{~mm}$ and $4 \mathrm{~mm}$. Very smooth surfaces and well-detailed products are produced with minimal draft angles. Oven curing and the drying of products between moulds are not required. Denser walls are obtained with the help of hot pressing. Type 3 thermoformed fibre products have similar appearance to that of thermoformed plastic materials.

d) Type 4 is processed MFPs, which require additional treatments beyond molding and drying. Type 4 products are often used for hot-pressed or after-pressed products, diecut or perforated products, and printed and coloured products (Didone et al. 2017).

Moulded fiber products are used in many different industries, and they provide innovative, eco-friendly packaging solutions. Generally, the main applications are in foodrelated products, disposable items, and industrial packaging products (Didone et al. 2017). For more than a century, MFPs have been used to protect other products and keep them organized. The most common use of MFPs is for egg packaging. The applications of disposable items and packaging requirements are continuously developing. Therefore, these products require new packaging solutions. With the development of Type 3 MPS production, it became possible to produce special packaging that is as customizable as plastic packaging items.

The use of recycled paper sources in MFP production makes them beneficial to nature. Flowerpots produced from recycled paper can easily be punctured by the roots of plants and decompose in the soil (Aguerre and Gavazzo 2016). Toy production mostly depends on plastic materials. Degradation of these materials in nature takes a very long time, which causes pollution. Further, the hardness of toys produced from plastics can injure children. This study aimed to develop a new kind of bleached softwood sulphate pulp-based toy with the Type 3 MFP production method to decrease child injuries caused by hard plastic-based toys and the harmful effects of plastics on the environment by the replacement of non-degradable materials.

\section{EXPERIMENTAL}

\section{Materials}

Bleached pine sulphate pulp was used as the raw materials in this research in the form of air-dry sheets. They were obtained from the G.A. Paper International (Markham, Ontario, Canada) with Forest Stewardship Council (FSC) Certification. The fibre 
properties of the raw materials were determined with Optest Fiber Quality Analysis (LDA02145; OpTest Equipment Inc., Hawkesbury, Canada) and are shown in Table 1.

Table 1. Bleached Softwood Sulphate Pulp Fibre Length, Fine Content, and Fibre Width

\begin{tabular}{|c|c|c|c|c|c|}
\hline \multicolumn{3}{|c|}{ Fiber Length $(\mathrm{mm})$} & \multicolumn{2}{c|}{ Fine Content $(\%)$} & Average Width $(\mu \mathrm{m})$ \\
\hline Arithmetic & $\begin{array}{c}\text { Length } \\
\text { Weighted }\end{array}$ & Weight Weighted & Arithmetic & $\begin{array}{c}\text { Length } \\
\text { Weighted }\end{array}$ & Arithmetic \\
\hline $0.939 \pm 0.059$ & $1.884 \pm 0.057$ & $2.527 \pm 0.055$ & $28.50 \pm 0.815$ & $3.59 \pm 0.105$ & $25.0 \pm 0.170$ \\
\hline
\end{tabular}

The toy design and the moulds were developed with Siemens NX CAD computer aided design program. Then, the prototype moulds were manufactured from EN-AN 5083 T6 aluminum blocks (Altek, İstanbul, Turkey) with a computer numerical control (CNC) machine (Chiron FZ-15, Chiron Group, Tuttlingen, Germany). To examine the effects of refining on the physical properties of the produced toys, bleached softwood sulphate pulp was refined to different freeness levels. The laboratory disc refiner used was obtained from Universal Engineering Corporation (Pradesh, India). To produce toy samples, Type 3 MFP production machinery was used. Generally, the system consists of a pulp mixing tank, a moulding unit, a drying unit and a vacuum pump. A similar unit was used to shape the composite natural fiber reinforcement structure in plate form according to Sarikaya et al. (2019). The produced toy samples are shown in Fig. 1, and the physical properties of the moulded fiber toy samples are given in Table 2 .

(a)
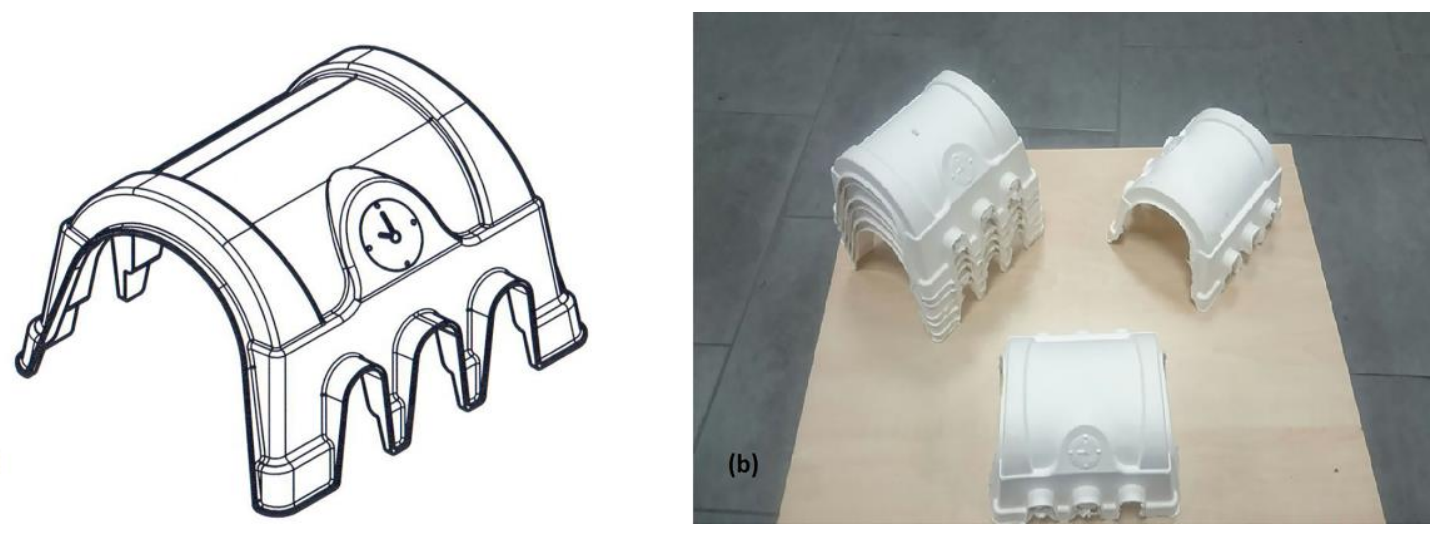

Fig. 1. The designed toy (a) and prototypes produced from bleached softwood sulphate pulp (b)

Table 2. Physical Properties of Produced Toy Samples

\begin{tabular}{|c|c|c|c|}
\hline \multirow{2}{*}{ Weight $(\mathrm{g})$} & \multicolumn{3}{|c|}{ Dimensions $(\mathrm{mm})$} \\
\cline { 2 - 4 } & Width & Length & Height \\
\hline $30.0 \pm 0.1$ & $132 \pm 2$ & $155 \pm 2$ & $90 \pm 1$ \\
\hline
\end{tabular}

In addition, alkyl ketene dimer (AKD) was used to restrict water absorption in the produced prototypes. This internal sizing agent was obtained from Diper Company (İzmir, Turkey) under the brand name of DR-SIZE CSD 222. 


\section{Methods}

The fibre samples were converted to pulp slurry with an Adirondack Formax Maelstrom Laboratory Pulper (Washington, NY, USA) at 3.5\% consistency for 12 min of mixing. Pulp samples were analyzed with an Optest fiber quality analyzer (OpTest Equipment Inc., Hawkesbury, Canada) for fibre length, fibre width, and fine content according to ISO 16065-1 (2014). A Labtech PFI beater (Québec, Canada) was used for laboratory refining experiments according to ISO 5264-2 (2011). After refining, the drainage properties of the pulps were tested with a Schopper Riegler Freeness Tester (Regmed, Osasco, Brazil) according to ISO 5267-1 (1999). Then, the pulp samples were used for the production of 10 handsheet samples of $75 \mathrm{~g} / \mathrm{m}^{2}$. For these production sets, a Regmed laboratory sheet former type rapid Köthen model RK-21 (Regmed Schopper Riegler, Osasco, Brazil) was used according to ISO 5269-2 (2004). To measure the tensile strength properties of the produced handsheets, a TMI horizontal tensile tester model No. K465 (New Castle, DE, USA) was used according to ISO 1924-3 (2005).

Five kg of air-dry bleached softwood sulphate fibres were converted to pulp slurry as described above. Then, pulp samples were refined with a laboratory disc refiner (Universal Engineering Corporation, Pradesh, India) at 3.5\% consistency until the desired pulp freeness was reached with a $1.0-\mathrm{mm}$ gap between refining discs. Then, the prepared pulp was transferred to a sample production machine, and the moulds for toy production were placed on the moulding machine. The formation mould, the surface of which was covered with a perforated screen, was submerged into the pulp slurry, and vacuuming was performed. Wet fibres covered the surface of this mould because water passed through the screen and the fibres could not. Next, the wet fibre form was transferred to a drying unit. In the drying unit, the male and female moulds were heated to $280{ }^{\circ} \mathrm{C}$ with a cartridge heater. The wet product was kept between drying moulds until the drying process was complete.

The whiteness, brightness, and yellowness of the prototype toys were measured with an Elrepho Datacolor (Lawrenceville, NJ, USA) according to ASTM E313 (2015), ISO 2469 (2014), and DIN 6167 (1980), respectively. Compression strength measurements were made with a TLS Minival compression tester (TechLabSystems, Lezo, Spain), and ten samples of each kind were measured at different relative humidity conditions.

Then, the samples were conditioned for $24 \mathrm{~h}$ in a Nüve Climate Cabin TK 25 (Nüve, Ankara, Turkey) at constant temperature of $23{ }^{\circ} \mathrm{C}$ and $38 \%, 60 \%$, and $90 \%$ relative humidity. After conditioning, moisture content measurements of the samples were carried out according to ISO 287 (2009). To examine the water absorption behaviour of the toy samples, prototypes were produced with and without AKD addition. The amount of added AKD was kept constant at 3.0\% of the total bone dry pulp when it was added. To allow clear comparison between these samples, their water absorption properties were measured according to ISO 525 (2014) via the Cobb test method with a Regmed Cobb tester (Osasco, Brazil). The air permeability of the sample toys was determined according to ISO 5636-3 (2013) via a TMI roughness and air permeability tester (New Castle, DE, USA). Further, the sample toys were tested for suitability according to EN 71-3:2013+A1(2014) in terms of migration element limits. Three prototypes were used for toxic element sample preparation. It was tested for nineteen restricted toxic material with acid extraction method and values were determined by Inductively Coupled Plasma-ICP_MS. 


\section{RESULTS AND DISCUSSION}

The Schopper Riegler freeness results for the PFI refined pulps with different numbers of revolutions are given in Fig. 2. The results show that ${ }^{\circ} \mathrm{SR}$ freeness value increased with increasing number of revolutions. Thus, the drainage property of the pulp decreased as the number of revolutions increased. Therefore, it became harder to separate the fibres and water from each other. Handsheet samples were produced with different numbers of revolutions, and their horizontal tensile index was tested. The obtained results are given in Fig. 3.

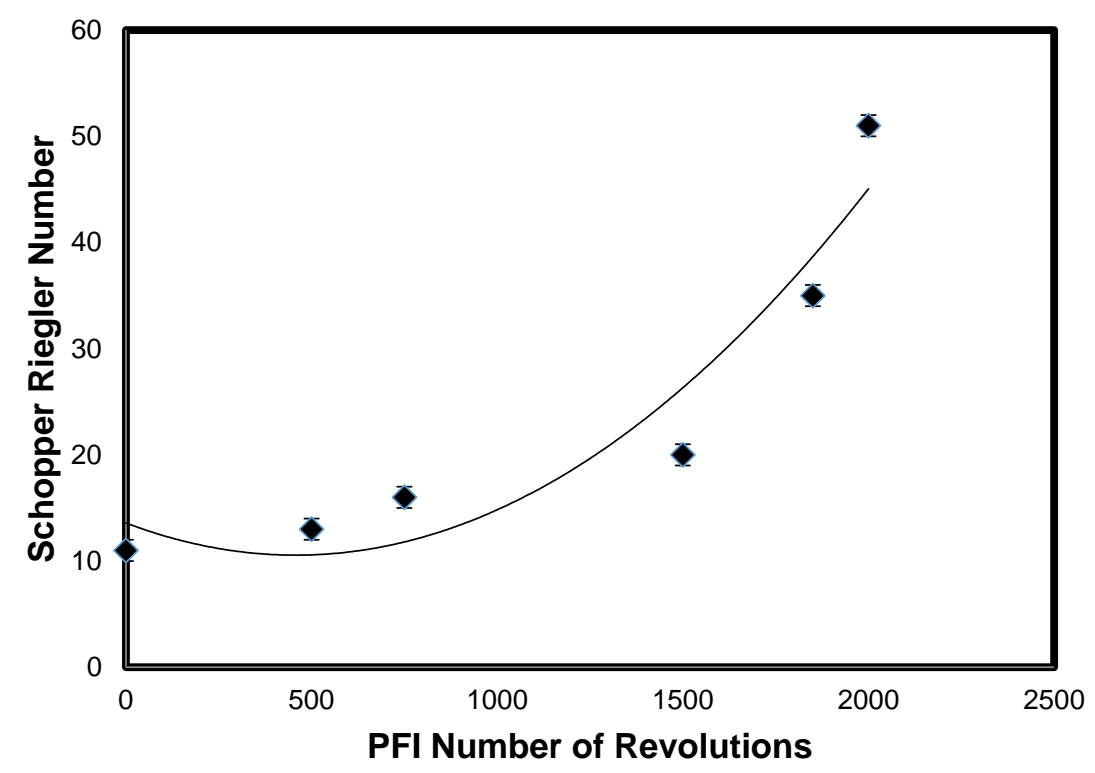

Fig. 2. The ${ }^{\circ} \mathrm{SR}$ development of the bleached softwood sulphate pulp

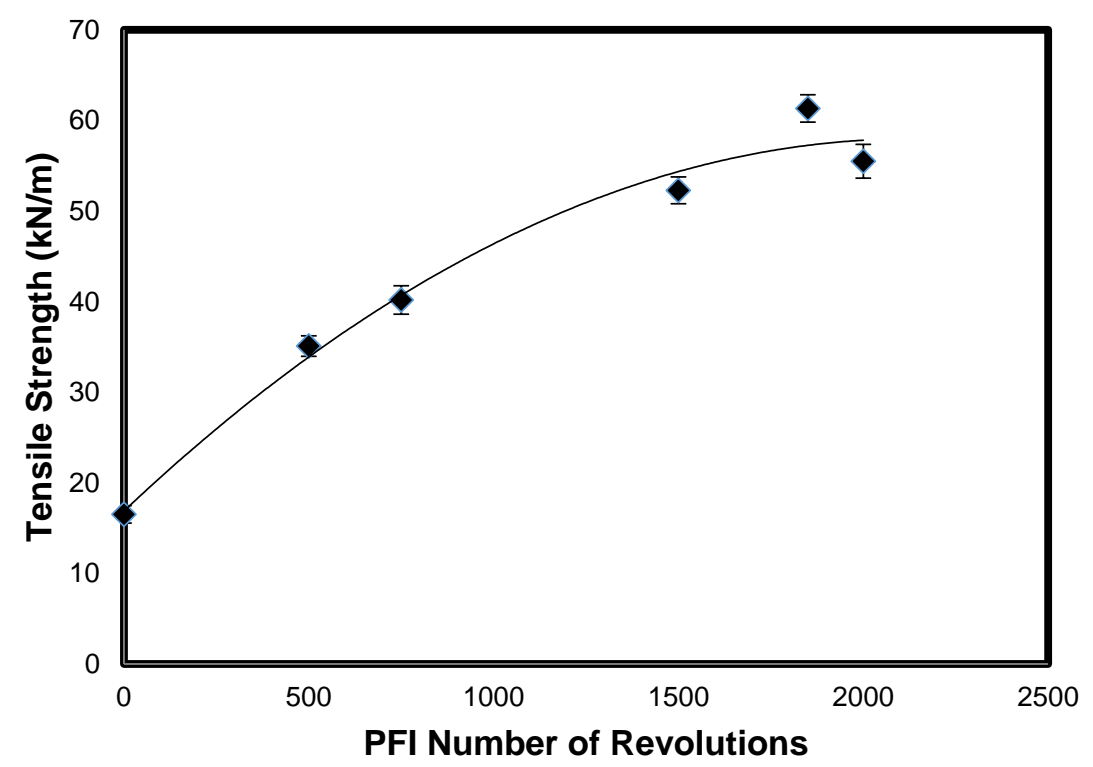

Fig. 3. The tensile index results of the bleached softwood sulphate pulp 
Tensile index is an indicator of fibre-fibre bonding ability. Tensile strength increased rapidly with increasing number of PFI revolutions until 1850 revolutions. At above 1850 revolutions, a plateau in the tensile index was observed.

The pulp used for toy sample production was refined to three different freeness levels, which were $25{ }^{\circ} \mathrm{SR}, 35{ }^{\circ} \mathrm{SR}$, and $45{ }^{\circ} \mathrm{SR}$. The colour analysis results of the prototypes are given in Table 3.

Table 3. Optical Properties of Prototypes and ${ }^{\circ} \mathrm{SR}$ Freeness Level

\begin{tabular}{|c|c|c|c|}
\hline \multirow{2}{*}{ Schopper Number $\left({ }^{\circ} \mathrm{SR}\right)$} & \multicolumn{3}{|c|}{ Optical Properties } \\
\cline { 2 - 4 } & Brightness & Yellowness & Whiteness \\
\hline 25 & 90.27 & 8.15 & 75.71 \\
\hline 35 & 83.63 & 8.48 & 67.30 \\
\hline 45 & 80.05 & 8.89 & 62.64 \\
\hline
\end{tabular}

The brightness and whiteness values of produced prototypes decreased with increasing pulp refinement. In contrast, yellowness values increased slightly as refinement increased. To examine the effects of environmental humidity changes on product behavior, prototype samples were conditioned in a climate cabin at $23{ }^{\circ} \mathrm{C}$ and $38 \%, 60 \%$, and $90 \%$ relative humidity for $24 \mathrm{~h}$. Then, box compression test (BCT) strengths were measured, and the results are presented in Fig. 4.

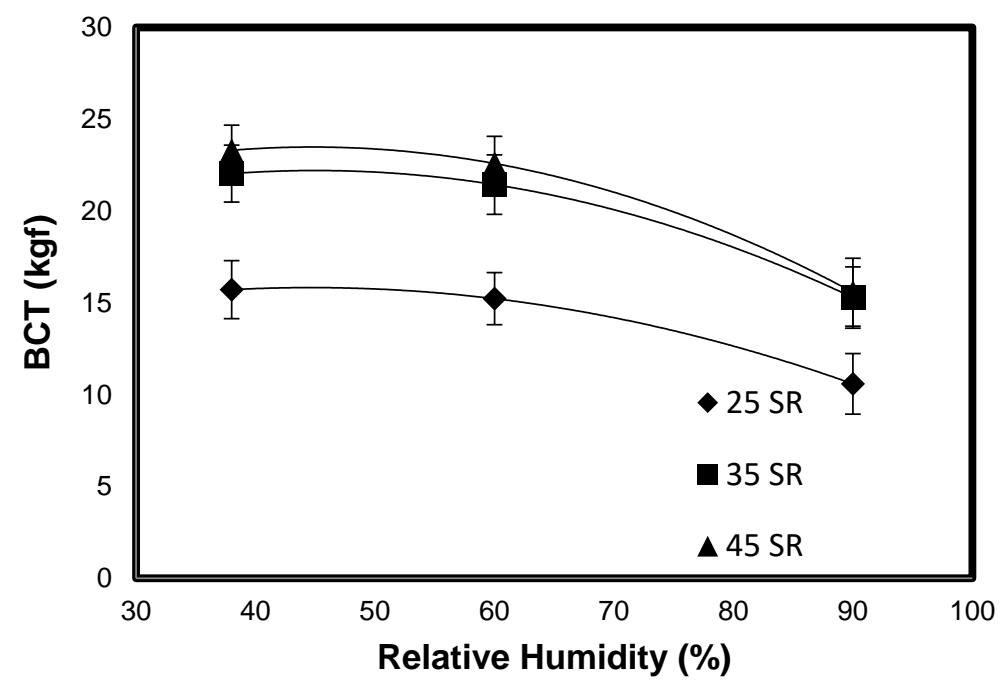

Fig. 4. Relative humidity and BCT strength

The BCT strength values of the prototypes did not change remarkably up to $60 \%$ relative humidity. However, high relative humidity values, such as $90 \%$, caused a reduction in BCT strength values for samples produced from pulps with different freeness levels. The compression strength of the prototypes increased rapidly when the freeness level of the pulp increased from $25{ }^{\circ} \mathrm{SR}$ to $35^{\circ} \mathrm{SR}$. However, compression strength increased more slowly when the freeness level of the pulp increased from $35{ }^{\circ} \mathrm{SR}$ to $45^{\circ} \mathrm{SR}$. Therefore, the refining of the pulp had superior influence on compression strength until $35{ }^{\circ} \mathrm{SR}$. However, the increasing effect of refining on compression strength decreased between 35 ${ }^{\circ} \mathrm{SR}$ and $45^{\circ} \mathrm{SR}$. 
The moisture levels in the samples after conditioning at different relative humidity values are given in Table 4.

Table 4. Relative Humidity and Product Moisture Content

\begin{tabular}{|c|c|c|c|}
\hline \multirow{2}{*}{ Relative Humidity (\%) } & \multicolumn{3}{|c|}{ Product Moisture Content (\%) } \\
\cline { 2 - 4 } & $25^{\circ} \mathrm{SR}$ & $35^{\circ} \mathrm{SR}$ & $45^{\circ} \mathrm{SR}$ \\
\hline 38 & 5.43 & 5.50 & 5.48 \\
\hline 60 & 7.23 & 7.10 & 7.15 \\
\hline 90 & 12.74 & 12.94 & 13.06 \\
\hline
\end{tabular}

Product moisture content increased due to capturing water from the air when environmental relative humidity was raised. However, the refining did not influence the balanced moisture level of products because there was no noticeable difference between prototype moisture contents across different pulp freeness levels. The water absorption properties of samples were measured with Cobb Tests, and the obtained results are given in Table 5. In general, Cobb Testing is not appropriate for unsized papers. However, to make a clear comparison of samples with and without AKD, Cobb Testing was applied to each sample type. Water absorption values decreased remarkably when AKD was used. Further, when the pulp freeness level increased with increasing refinement, water absorption decreased.

Table 5. Cobb Test Results of Prototypes

\begin{tabular}{|c|c|c|}
\cline { 2 - 3 } \multicolumn{1}{c|}{} & Without AKD & With AKD \\
\hline Schopper Number $\left({ }^{\circ} \mathrm{SR}\right)$ & Cobb30 $\left(\mathrm{gr} / \mathrm{m}^{2}\right)$ & Cobb30 $\left(\mathrm{gr} / \mathrm{m}^{2}\right)$ \\
\hline 25 & 1457 & 27 \\
\hline 35 & 1261 & 19 \\
\hline 45 & 1113 & 18 \\
\hline
\end{tabular}

The results of air permeability testing at $1.47 \mathrm{kPa}$ test pressure are given in Fig. 5 .

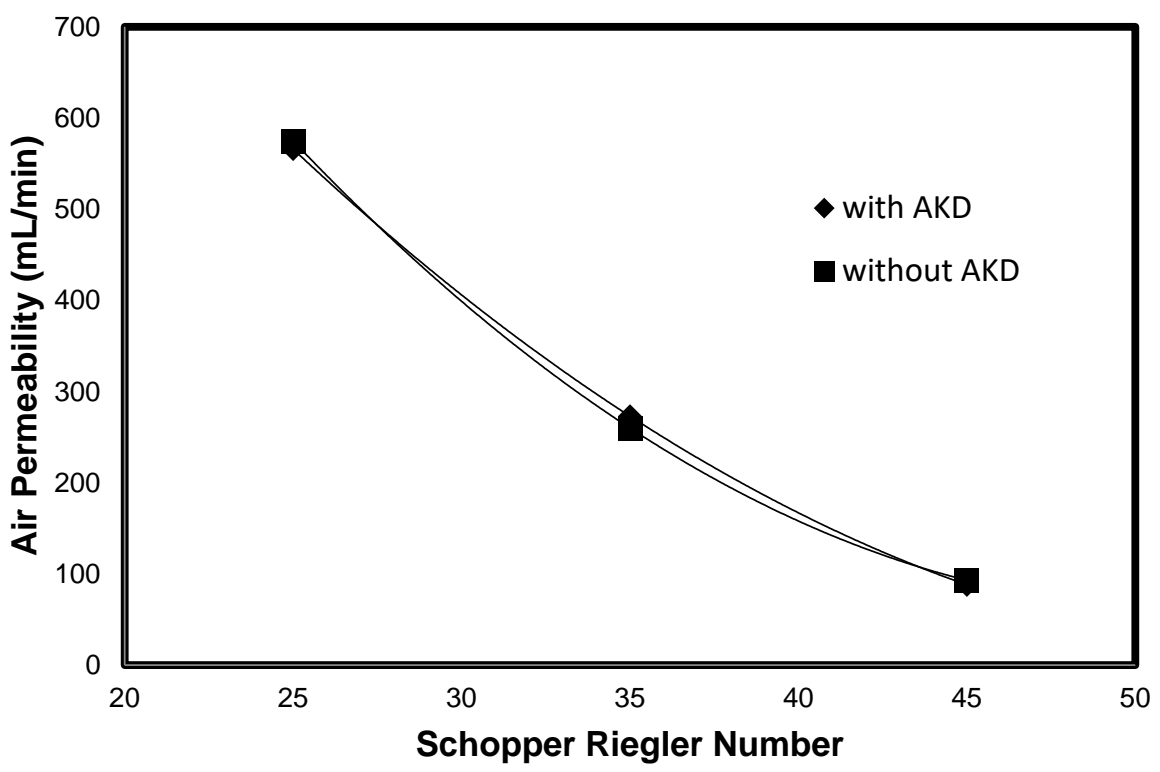

Fig. 5. Air permeability and ${ }^{\circ} \mathrm{SR}$ at $1.47 \mathrm{kPa}$ test pressure 
The air permeability of samples decreased when pulp freeness level increased. The use of AKD during production did not have any major effect on the air permeability of pulp samples.

Chemical analysis results of the prototypes are given in Table 6 according to EN 71-3:2013+A1(2014) in terms of migration element limits.

Table 6. Restricted Chemical Analysis Results on Produced Prototypes

\begin{tabular}{|c|c|c|c|}
\cline { 2 - 4 } \multicolumn{1}{c|}{} & Result $(\mathrm{ppm})$ & Detection Limit $(\mathrm{ppm})$ & Maximum Allowed $(\mathrm{ppm})$ \\
\hline Antimony $(\mathrm{Sb})$ & Not Detected & 0.125 & 560 \\
\hline Arsenic $(\mathrm{As})$ & Not Detected & 0.125 & 47 \\
\hline Barium $(\mathrm{Ba})$ & Not Detected & 0.125 & 18750 \\
\hline Cadmium $(\mathrm{Cd})$ & Not Detected & 0.125 & 17 \\
\hline Chromium $(\mathrm{III})$ & Not Detected & 0.125 & 460 \\
\hline Chromium $(\mathrm{VI})$ & Not Detected & 0.125 & 0.2 \\
\hline Lead $(\mathrm{Pb})$ & Not Detected & 0.125 & 160 \\
\hline Mercury $(\mathrm{Hg})$ & Not Detected & 0.0125 & 94 \\
\hline Selenium $(\mathrm{Se})$ & Not Detected & 0.125 & 460 \\
\hline Aluminium $(\mathrm{Al})$ & 8.4 & 0.125 & 150000 \\
\hline Boron $(\mathrm{B})$ & Not Detected & 0.125 & 130 \\
\hline Cobalt $(\mathrm{Co})$ & Not Detected & 0.125 & 7700 \\
\hline Copper $(\mathrm{Cu})$ & Not Detected & 0.125 & 15000 \\
\hline Manganese $(\mathrm{Mn})$ & 3.7 & 0.125 & 930 \\
\hline Nickel $(\mathrm{Ni})$ & 3.7 & 0.125 & 56000 \\
\hline Strontium $(\mathrm{Sr})$ & 11.2 & 0.125 & 180000 \\
\hline Tin $(\mathrm{Sn})$ & 11.2 & 1.250 & 12 \\
\hline Organic tin & 11.2 & 0.125 & 46000 \\
\hline Zinc $(\mathrm{Zn})$ & 3.6 & 0.125 & \\
\hline
\end{tabular}

The results indicated that the toys were within the limits for all restricted chemicals. Therefore, the produced prototypes complied with EN 71-3:2013+A1(2014) in terms of migration element limits.

\section{CONCLUSIONS}

1. Bleached softwood sulphate pulp was deeply investigated in terms of fibre quality, drainage change, strength development, water absorption, air permeability, and optical properties with respect to refining. Refining was an efficient way to develop strength through pulp treatment before toy prototypes are produced from bleached softwood sulphate pulp.

2. The obtained samples had no hygiene problems and were compatible with the EN 713:2013+A1(2014) in terms of migration element limits. In addition, they can be reused as raw material in recovered paper facilities for further production of other paper products. 
3. The water absorption properties of prototypes could be improved with AKD sizing agent use. In addition, AKD use did not influence the air permeability of prototypes.

4. The brightness values of all produced samples were above $80 \% \mathrm{ISO}$, and the prototypes could carry $22 \mathrm{kgf}$ load without causing permanent damage at room conditions when using softwood sulphate pulp that is refined to above $35^{\circ} \mathrm{SR}$ freeness at this geometry and weight.

5. The development of this toy prototype showed that MFP products can be produced and used as an end-use product. With the implementation of these kinds of products, the use of petroleum-based products could decrease.

6. Design and mould manufacturing are starting points for different types, forms, and functionalities of toys.

\section{ACKNOWLEDGMENTS}

This work was supported by the Scientific and Technological Research Council of Turkey (TÜBİTAK) Industrial R\&D Projects Support Programme under the Project Number 3160117 and name of "Development of Toy from Bleached Paper Pulp for Children." The authors also thank Dentaş Paper Industry, the leading producer and developer of MFPs in Turkey, for providing pulp and paper laboratory facilities for this research.

\section{REFERENCES CITED}

Aguerre, Y. S., and Gavazzo, G. B. (2016). "Lignocellulosic recycled materials to design molded products: Optimization of physical and mechanical properties," Journal of Materials Science and Engineering A 6(7-8), 222-231 DOI: 10.17265/21616213/2016.7-8.005

ASTM E313 (2015). "Standard practice for calculating yellowness and whiteness indices from instrumentally measured color coordinates," ASTM International, West Conshohocken, PA, USA.

Didone, M., Saxena, P., Meijer, E.-B. Tosello, G., Bissacco, G., McAloone, T. C., Pigosso, D. C. A., and Howard, T. J. (2017). "Moulded pulp manufacturing: Overview and prospects for the process technology," Packaging Technology and Science 30(6), 231-249. DOI: 10.1002/pts.2289

DIN 6167 (1980). "Description of yellowness of near-white or near-colourless materials," Deutsches Institut Fur Normung [German Institute for Standardization], Berlin, Germany.

EN 71-3:2013+A1(2014) "Safety of toys - Part 3: Migration of certain elements," European Standard, CEN Amendment I, Brussels, Belgium.

ISO 287 (2009). "Paper and board - Determination of moisture content of a lot Oven-drying method," International Organization for Standardization, Geneva, Switzerland.

ISO 525 (2014). "Paper and board - Determination of water absorptiveness — Cobb method,” International Organization for Standardization, Geneva, Switzerland. 
ISO 2469 (2014). "Paper, board and pulps - Measurement of diffuse radiance factor (diffuse reflectance factor)," International Organization for Standardization, Geneva, Switzerland.

ISO 5264-2 (2011). "Pulps — Laboratory beating — Part 2: PFI mill method," International Organization for Standardization, Geneva, Switzerland.

ISO 5267-1 (1999). "Pulps - Determination of drainability - Part 1: Schopper-Riegler method," International Organization for Standardization, Geneva, Switzerland.

ISO 5269-2 (2004). "Pulps - Preparation of laboratory sheets for physical testing Part 2: Rapid-Köthen method," International Organization for Standardization, Geneva, Switzerland.

ISO 5636-3 (2013). "Paper and board - Determination of air permeance (medium range) - Part 3: Bendtsen method," International Organization for Standardization, Geneva, Switzerland.

ISO 16065-1 (2014). "Pulps - Determination of fibre length by automated optical analysis - Part 1: Polarized light method," International Organization for Standardization, Geneva, Switzerland.

ISO 1924-3 (2005). "Paper and board - Determination of tensile properties - Part 3: Constant rate of elongation method $(100 \mathrm{~mm} / \mathrm{min})$," International Organization for Standardization, Geneva, Switzerland.

Ji, H., Wang, H., and Chen, J. (2008). "Mechanical behaviors of molded pulp material," in: International Conference on Experimental Mechanics 2008 and Seventh Asian Conference on Experimental Mechanics, Nanjing, China, pp. 8-11.

Keyes, F. K. (1890). "Method of molding pulp articles," US Patent No. 424,003. U.S. Patent Office.

Keyes, M. L. (1903). “Apparatus for making pulp articles,” US Patent No. 740,023. U.S. Patent Office

Sarikaya, E., Çallioğlu, H., and Demirel, H. (2019). "Production of epoxy composites reinforced by different natural fibers and their mechanical properties," Composites Part B: Engineering 167, 461-466. DOI: 10.1016/j.compositesb.2019.03.020

Wever, R., and Twede, D. (2007). "The history of molded fiber packaging: A 20th century pulp story," in: Proceedings of the 23rd IAPRI Symposium on Packaging, Windsor, England, pp. 1-8.

Article submitted: March 3, 2020; Peer review completed: May 31, 2020; Revised version received: June 24, 2020; Accepted: July 13, 2020; Published: July 21, 2020. DOI: 10.15376/biores. 15.3.6902-6911 